\title{
Bacterial contributions to delignification and lignocellulose degradation in forest soils with metagenomic and quantitative stable isotope probing
}

\author{
Roland C. Wilhelm $\mathbb{D}^{1} \cdot$ Rahul Singh $^{1} \cdot$ Lindsay D. Eltis $^{1} \cdot$ William W. Mohn ${ }^{1}$
}

Received: 8 January 2018 / Revised: 20 May 2018 / Accepted: 11 August 2018 / Published online: 26 September 2018

(c) The Author(s) 2018. This article is published with open access

\begin{abstract}
Delignification, or lignin-modification, facilitates the decomposition of lignocellulose in woody plant biomass. The extant diversity of lignin-degrading bacteria and fungi is underestimated by culture-dependent methods, limiting our understanding of the functional and ecological traits of decomposers populations. Here, we describe the use of stable isotope probing (SIP) coupled with amplicon and shotgun metagenomics to identify and characterize the functional attributes of lignin, cellulose and hemicellulose-degrading fungi and bacteria in coniferous forest soils from across North America. We tested the extent to which catabolic genes partitioned among different decomposer taxa; the relative roles of bacteria and fungi, and whether taxa or catabolic genes correlated with variation in lignocellulolytic activity, measured as the total assimilation of ${ }^{13} \mathrm{C}$-label into DNA and phospholipid fatty acids. We found high overall bacterial degradation of our model lignin substrate, particularly by gram-negative bacteria (Comamonadaceae and Caulobacteraceae), while fungi were more prominent in cellulosedegradation. Very few taxa incorporated ${ }^{13} \mathrm{C}$-label from more than one lignocellulosic polymer, suggesting specialization among decomposers. Collectively, members of Caulobacteraceae could degrade all three lignocellulosic polymers, providing new evidence for their importance in lignocellulose degradation. Variation in lignin-degrading activity was better explained by microbial community properties, such as catabolic gene content and community structure, than cellulose-degrading activity. SIP significantly improved shotgun metagenome assembly resulting in the recovery of several high-quality draft metagenome-assembled genomes and over 7500 contigs containing unique clusters of carbohydrate-active genes. These results improve understanding of which organisms, conditions and corresponding functional genes contribute to lignocellulose decomposition.
\end{abstract}

\section{Introduction}

The incomplete decomposition of woody biomass in coniferous forests is an important global carbon sink, with approximately one third of a gigaton of carbon accruing on an annual basis [1]. Lignocellulose decomposition is influenced by the structure and function of microbial

Electronic supplementary material The online version of this article (https://doi.org/10.1038/s41396-018-0279-6) contains supplementary material, which is available to authorized users.

\section{William W. Mohn}

wmohn@mail.ubc.ca

1 Department of Microbiology \& Immunology, Life Sciences Institute, University of British Columbia, Vancouver, BC V6T 1Z3, Canada communities [2,3] and terrestrial carbon cycling models increasingly parameterize these properties $[4,5]$. However, efforts are constrained by our rudimentary knowledge of the composition and ecology of decomposer populations, stemming from limitations of culture-dependent methods and the complexity of soil communities. The best characterized decomposers inhabit forest soil litter, where conditions favour rapid lignocellulose degradation [6,7], yet the decay of lignin-rich plant polymers in soil occurs in a continuum governed by conditions and substrate accessibility, resulting in diversified niches for decomposers [8-10]. To resolve the catabolic and ecological traits of decomposers, we must utilize culture-independent methods, like stable isotope probing (SIP), that better reflect in situ conditions.

The nature of microbial lignin-degradation is poorly described beyond the canonical breakdown of lignin in woody biomass by specialized, aerobic, litter-inhabiting 
wood-rot fungi. Yet, these fungi are largely absent in deeper mineral soil where conditions favour decomposition by bacteria [11], who represent the most likely lignin-degraders when oxygen is limited [12-14]. Several soil bacteria can degrade model lignin compounds in pure culture, suggesting a role in the catabolism of low-molecular weight, partially-degraded forms of lignin [15-21]. Knowledge of bacterial lignin-degradation in environmental contexts is limited, with all studies of soil degraders originating from tropical forests which describe active populations of predominantly Alpha and Gammaproteobacteria [13, 22]. The existing evidence for bacterial lignin-degradation demonstrates the need to characterize both bacterial and fungal populations and contrast their roles in different soil environments to better understand in situ the processes that govern the decomposition of lignocellulose.

Delignification rapidly increases the rate of lignocellulose decomposition and may have evolved primarily as a means of accessing more readily degradable plant carbohydrates, exemplified by the strategies of white and brown-rot Agaricomycota [23-25]. The capability to codegrade lignin and other lignocellulosic polymers has not been thoroughly explored in bacteria. There is some evidence for the co-metabolism of lignocellulosic polymers by various Streptomyces spp. [26], while a comparative genomics study revealed that cellulose-degrading bacteria also possess higher numbers of hemicellulases [27]. The extent to which catabolic traits are conserved within specific taxa versus communities will influence models of microbial decomposition. In the simplest case, the abundance of highly adapted, multi-substrate degrading taxa may predict rates of decomposition, which is supported by a small number of studies $[2,28]$. However, forces of genomic streamlining in bacteria lead to functional diversification among closely related species, particularly in extra-cellular processes that produce common goods [29], evident in the species-level conservation of bacterial endoglucanases [30]. A multi-substrate SIP experiment provides the means to identify whether forest soil decomposers can assimilate ${ }^{13} \mathrm{C}$ from various lignocellulosic polymers and, with shotgun metagenomic sequencing, determine whether their genomes encode the necessary suite of catabolic genes.

To address the above knowledge gaps, we utilized SIP microcosm-based experiments to investigate the composition and degradative potential of hemicellulose, cellulose and lignin-degrading populations from organic and mineral layer soils in coniferous forests across North America. The identity of degraders and their genomic content were assessed using amplicon and shotgun sequencing of DNA enriched in ${ }^{13} \mathrm{C}$ from labeled substrates. Lignocellulolytic activity was quantified according to the amount of ${ }^{13} \mathrm{C}$ assimilated into total DNA and phospholipid fatty acids (PLFA). The in situ abundances of lignocellulolytic populations were determined on the basis of previously reported pyrotag libraries from the same field samples $[31,32]$. This is currently the most comprehensive cultivation-independent study of lignocellulolytic populations in forest soils and yields new insights to the taxa responsible and the importance of certain catabolic gene families.

\section{Material and methods}

\section{Overview of sites and sample collection}

Soil samples were collected from five forest regions in North American chosen to encompass a range of climates, tree cover and soil conditions. Samples were collected from mature coniferous forest corresponding to 'reference' plots in the Long-Term Soil Productivity Study in northern Ontario $\left(\mathrm{BS}_{\mathrm{ON}}\right.$ and $\left.\mathrm{JP}_{\mathrm{ON}}\right)$, British Columbia $\left(\mathrm{IDF}_{\mathrm{BC}}\right)$, California $\left(\mathrm{PP}_{\mathrm{CA}}\right)$ and Texas $\left(\mathrm{LP}_{\mathrm{TX}}\right)$. Detailed descriptions of geographical locations, soil properties and sampling methods can be found in [31] as well as in Table S1. Samples were collected from three sites in each geographical region, except $\mathrm{IDF}_{\mathrm{BC}}$ where three plots were sampled from a single site. The organic layer (O-horizon) and the top $20 \mathrm{~cm}$ of mineral soil (A-horizon + occasionally upper B-horizon) were sampled separately (overview in Fig. 1a). Samples were kept at $4{ }^{\circ} \mathrm{C}$ during transport, sieved through 2-mm mesh and stored at $-80{ }^{\circ} \mathrm{C}$.

\section{Preparation of SIP soil microcosms and ${ }^{13} \mathrm{C}$-labeled substrates}

Microcosms were prepared with a minimum of three replicates by adding ${ }^{13} \mathrm{C}$-labeled hemicellulose, cellulose or lignin to soil from as many of the five regions as possible contingent on the availability of substrate (Fig. 1a). Microcosms were comprised of either $1 \mathrm{~g}$ (organic) or $2 \mathrm{~g}$ (mineral) dry wt soil in 30-mL serum vials adjusted to a moisture content of $60 \%$ (mineral) and $125 \%$ (organic) (w/ v). Microcosms were wetted and pre-incubated in the dark at $20{ }^{\circ} \mathrm{C}$ for one-week prior to the addition of $1 \%(\mathrm{w} / \mathrm{w})$ ${ }^{13} \mathrm{C}$-labeled cellulose or $0.8 \% \quad(\mathrm{w} / \mathrm{w})$ lignin. The hemicellulose-amended incubations were performed as part of a previous study examining the impacts of timber harvesting on decomposition using identical methods as described here for cellulose [33]. Each microcosm with ${ }^{13} \mathrm{C}$ labeled substrate was paired with an identical ${ }^{12} \mathrm{C}$-control' microcosm amended with the corresponding unlabeled substrate $\left(\sim 1.1 \%\right.$ atom $\left.{ }^{13} \mathrm{C}\right) .{ }^{12} \mathrm{C}$-control microcosms were used to estimate the natural abundance of ${ }^{13} \mathrm{C}$ in PLFAs and to control for the background presence of GC-rich DNA in higher density $\mathrm{CsCl}$ gradient fractions [34]. 


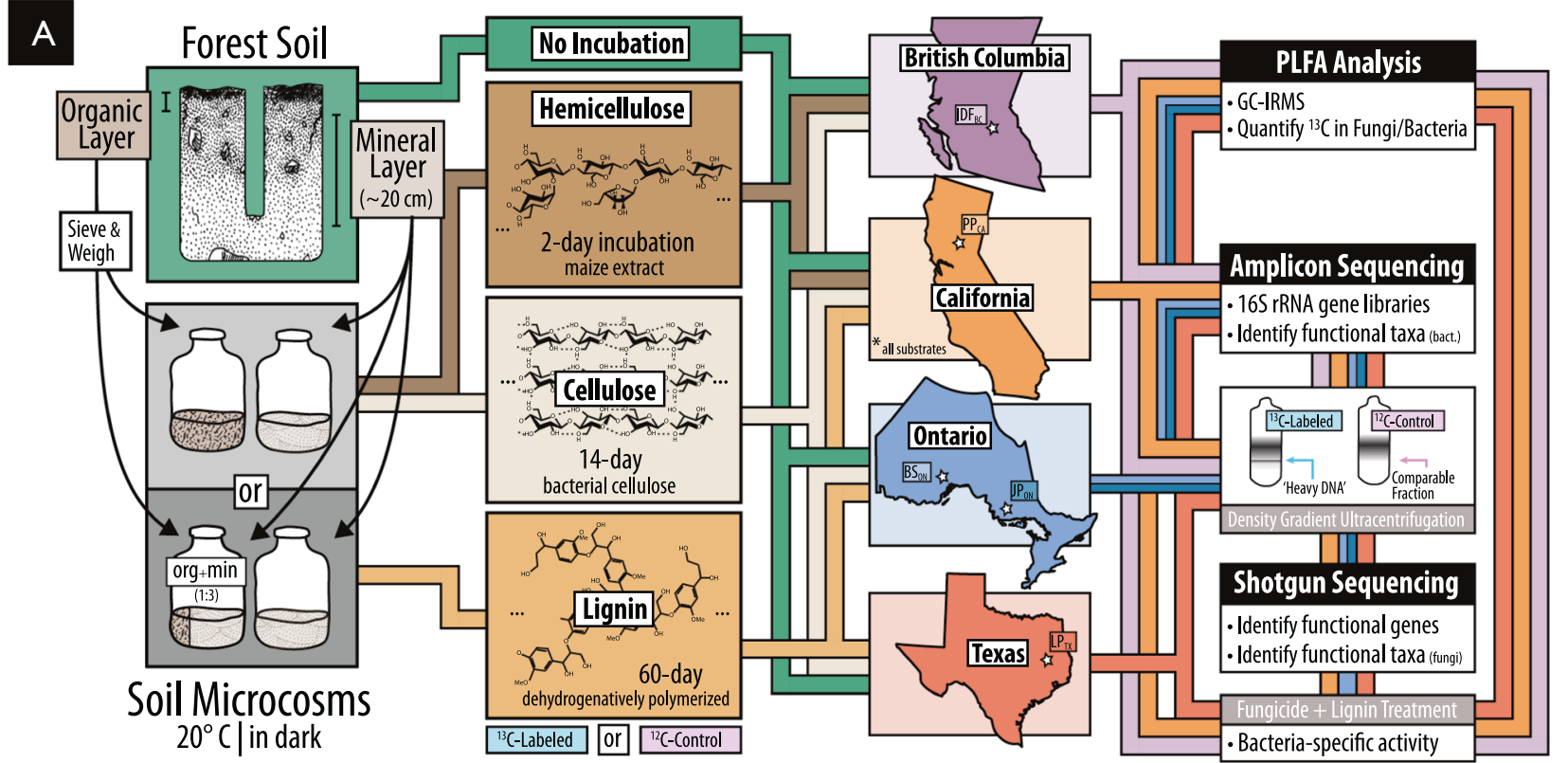

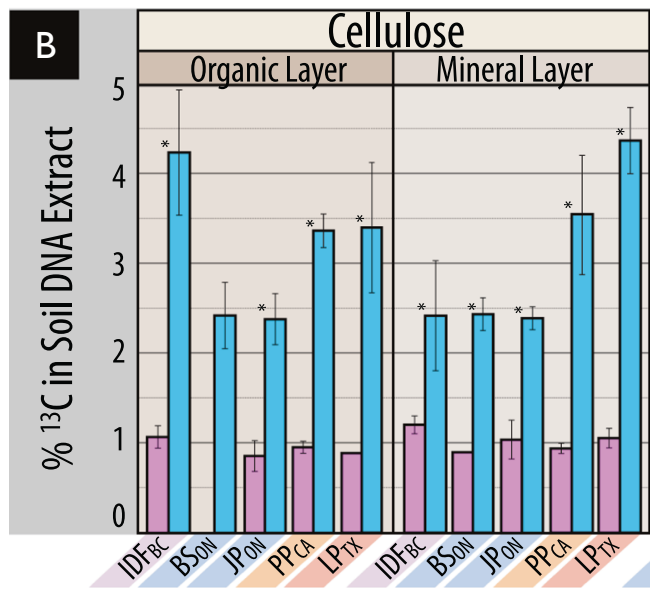

Fig. 1 (A) An overview of the samples and methods used in this study, including (b) evidence of the enrichment of ${ }^{13} \mathrm{C}$ in DNA extracted from soil amended with ${ }^{13} \mathrm{C}$-labeled or unlabeled substrate, and (c) for the separation and recovery of ${ }^{13} \mathrm{C}$-labeled DNA from heavy fractions of a cesium chloride density gradient. The schematic in A illustrates our use of organic and mineral layer soil from five forest regions

Bacterial cellulose was produced from Gluconacetobacter xylinus str. KCCM 10100 grown with either unlabeled or ${ }^{13} \mathrm{C}$-labeled glucose (99 atom $\%{ }^{13} \mathrm{C}$, Cambridge Isotope Laboratories, MA, USA) in Yamanaka medium as described in the Supplementary Methods. DHP lignin was synthesized from ring-labeled coniferyl alcohol using horseradish peroxidase as described [35]. Coniferyl alcohol was synthesized from ring-labeled vanillin $\left(75\right.$ atom $\%{ }^{13} \mathrm{C}$, Sigma Aldrich, CA) according to the reactions in Figure $\mathrm{S} 1$ with methods outlined in the Supplementary Methods. The DHP lignin had a weight average molecular weight $\left(\mathrm{M}_{\mathrm{w}}\right)$ of $2,624 \mathrm{~g} \cdot \mathrm{mol}^{-1}$ which equates to $\sim 14$ polymerized units of coniferyl alcohol. Yields for cellulose and incubated with or without one of three model constituents of lignocellulose. Due to limited quantities of ${ }^{13} \mathrm{C}$-labeled substrate, the complete pairing of all forest regions and substrates was not possible. In $(\mathbf{B} 0$ and $(\mathbf{C})$, Statistically supported differences between paired labeled and unlabeled treatments $(t$-test; $p<0.01)$ are designated with an asterisk $(*)$

lignin were approximately $12 \%$ and $18 \%(\mathrm{w} / \mathrm{w})$ and were labeled at $\sim 99$ and $60 \%$ atom $\%{ }^{13} \mathrm{C}$, respectively.

Microcosms were incubated at $20^{\circ} \mathrm{C}$ for 14 days (cellulose) or 60 days (lignin) or 2 days (hemicellulose; [33]). The incubation length for this study was optimized by preliminary time-course experiments described in [36]. To overcome poor ${ }^{13} \mathrm{C}$-labeling of microbial biomass in organic soils from DHP-lignin, organic soils were mixed 1:3 with corresponding double-autoclaved mineral soil to dilute pre-existing organic matter. Following incubation, soil samples were lyophilized and stored at $-80{ }^{\circ} \mathrm{C}$ until processing. All SIP-PLFA, SIP-pyrotag and SIPmetagenomic data were generated from the same 
microcosm unless otherwise stated. Due to limited quantities of ${ }^{13} \mathrm{C}$-substrate, SIP-lignin microcosms were prepared with soil from only $\mathrm{BS}_{\mathrm{ON}}, \mathrm{PP}_{\mathrm{CA}}$ and $\mathrm{LP}_{\mathrm{TX}}$, while SIPhemicellulose data was available for $\mathrm{IDF}_{\mathrm{BC}}$ and $\mathrm{PP}_{\mathrm{CA}}$ (see Table S2 for summary of data). To determine the lignolytic activity solely by bacteria, eight additional soil microcosms were prepared with ${ }^{13} \mathrm{C}$-lignin amended mineral soil and incubated with or without weekly additions of two fungicides: $1 \mathrm{mg} \cdot \mathrm{g}^{-1}$ soil cylcoheximide plus $1.2 \mathrm{mg} \cdot \mathrm{g}^{-1}$ soil fungizone (amphotericin B).

\section{SIP-PLFA analysis}

PLFAs were extracted from $0.75 \mathrm{~g}$ (organic) or $1.0 \mathrm{~g}$ (mineral) dry wt soil according to [37] and ${ }^{13} \mathrm{C}$-content was analyzed using ion ratio mass spectrometry (UBC Stable Isotope Facility) ported with gas chromatography as detailed in [38]. Peak identification was based on retention time compared against two reference standards: bacterial acid methyl-ester standard (47080-0; Sigma-Aldrich, St. Louis) and a 37-Component fatty acid methyl-ester mix (47885-U; Sigma-Aldrich, St. Louis). For details on the treatment of unidentifiable, but ${ }^{13} \mathrm{C}$-labeled, peaks and taxonomic designations consult the Supplementary Methods.

\section{Preparation of amplicon and shotgun metagenome libraries}

DNA was extracted from soil $(0.5 \mathrm{~g})$ using the FastDNA ${ }^{\mathrm{TM}}$ Spin Kit for Soil (MPBio, Santa Ana, CA) following the manufacturer's protocol. ${ }^{13} \mathrm{C}$-enriched DNA was separated using cesium chloride density centrifugation per methods outlined by [39] with minor modifications (see Supplementary Methods). DNA from heavy fractions (1.727-1.735 $\mathrm{g} \cdot \mathrm{mL}^{-1}$; typically $\left.\mathrm{F}_{1}-\mathrm{F}_{7}\right)$ was pooled, desalted and concentrated using Amicon Ultra- $0.5 \mathrm{~mL}$ filters (EMD Millipore, MA, USA). DNA from ${ }^{12} \mathrm{C}$-controls was treated identically; however, the total DNA recovered from those heavy fractions of ${ }^{12} \mathrm{C}$-controls was insufficient for sequencing library preparation, resulting in the need to pool additional fractions $\left(\mathrm{F}_{1}-\mathrm{F}_{9}\right)$. The $\%$ atom ${ }^{13} \mathrm{C}$ of soil DNA extracts and DNA from heavy fractions was quantified according to [36]. All other DNA quantitation was performed using Pico-Green fluorescent dye (ThermoFisher, MA, USA).

PCR amplification was performed on bacterial $16 \mathrm{~S}$ rRNA gene (V1-V3) using barcoded primers as described in [40]. PCR reactions were performed in triplicate and pooled prior to purification. Samples were sequenced using the Roche 454 Titanium platform (GS FLX+) at the McGill University and Genome Québec Innovation Centre, yielding an average of 8400 bacterial reads per sample with a minimum length of 250-bp following quality processing. All $16 \mathrm{~S}$ rRNA gene libraries are stored at the European Nucleotide Archive (ENA) under the study accession PRJEB12502. Identically prepared $16 \mathrm{~S}$ rRNA gene amplicon libraries for SIP-hemicellulose [33] and for corresponding unincubated field soil samples [32] were reanalyzed in the present study, following retrieval from the ENA.

Whole shotgun metagenomes were prepared from ${ }^{13} \mathrm{C}$ enriched or ${ }^{12} \mathrm{C}$-control DNA using either the Nextera DNA Sample Preparation Kit (Illumina Inc., CA, USA) for SIP-cellulose microcosm (40-50 ng template DNA), or the Nextera XT DNA Sample Preparation Kit (Illumina Inc., CA, USA) for SIP-lignin (1 ng), due to lower recovery of ${ }^{13} \mathrm{C}$-enriched DNA. The two sequencing library preparations produced very similar metagenomic profiles in a direct comparison [41]. Four libraries were multiplexed per lane of Illumina HiSeq $2500(2 \times 100$-bp $)$ and were grouped based on similar average fragment sizes based on fragment profiles from a 2100 Bioanalyzer (Agilent Technologies) All raw and assembled shotgun metagenomic data is available under ENA accession PRJEB12502, with an overview of accessioned data available in Table S3.

\section{Bioinformatic and statistical analyses}

16S rRNA gene amplicon libraries for all three SIPsubstrates were quality filtered and simultaneously processed using mothur according to the Schloss '454 SOP' (accessed November 2015; [42]) and clustered into operational taxonomic units (OTUs) at $0.01 \%$ dissimilarity. Taxonomic classification was performed using the RDP Classifier [43] with the GreenGenes database for 16S rRNA genes (database gg_13_8_99; August 2013). All OTU counts were normalized to total counts per thousand reads. All related count tables, classifications and sample data is provided as phyloseq objects in the Supplementary Data. Phylogenetic trees were prepared by placing sequences into the pre-aligned SILVA tree ([44]; 'SSURef_NR99_123_SILVA_12_07_15') using maximum parsimony in ARB [45].

Shotgun metagenome libraries from SIP-cellulose and SIP-lignin were quality preprocessed with Trimmomatic ([46]; v. 0.32) and FastX Toolkit ([47]; v. 0.7). Individual metagenomes were assembled using Ray-meta [48]. Metagenomes were also composited by location and soil layer and assembled with the low-memory assembler MEGAHIT ([49]; v. 1.0.2). Contigs from composited metagenomes were binned into metagenome-assembled genomes (MAGs) using MetaBAT ([50]; v. 0.18.6) based on read mapping with Bowtie2 [51]. The quality of draft genome bins was assessed using CheckM [52] and the lowest common 
Fig. 2 Designations of all putatively hemicellulolytic, cellulolytic and lignolytic taxa based on differential abundance between ${ }^{13} \mathrm{C}$ and ${ }^{12} \mathrm{C}$-pyrotag (bacterial OTUs) or unassembled metagenomes (fungal taxonomy based on LCA). The lowest possible classifications are given with the prefix corresponding to taxonomic rank. The abundance of each taxon in situ (i.e., in unincubated field soil) is represented by a scaled circle that was coloured (and given a coloured background) if that taxon was attributed lignocellulolytic activity in that forest region. Uncoloured (white) circles indicate SIP data was not available for that forest region (consult Fig. 1a for overview) and grey circles indicate SIP data was available, but the taxon was not attributed activity. The averaged ratio of abundance in ${ }^{13} \mathrm{C}$ versus ${ }^{12} \mathrm{C}$ libraries for each taxonomic classification (i.e., all OTUs within each taxon) is displayed for each substrate. A lemniscate $(\infty)$ indicates cases where that taxon was detected in only ${ }^{13} \mathrm{C}$ libraries. A full account of all enriched OTUs and citations for all reported catabolic activity is available in Supplementary

Table S4

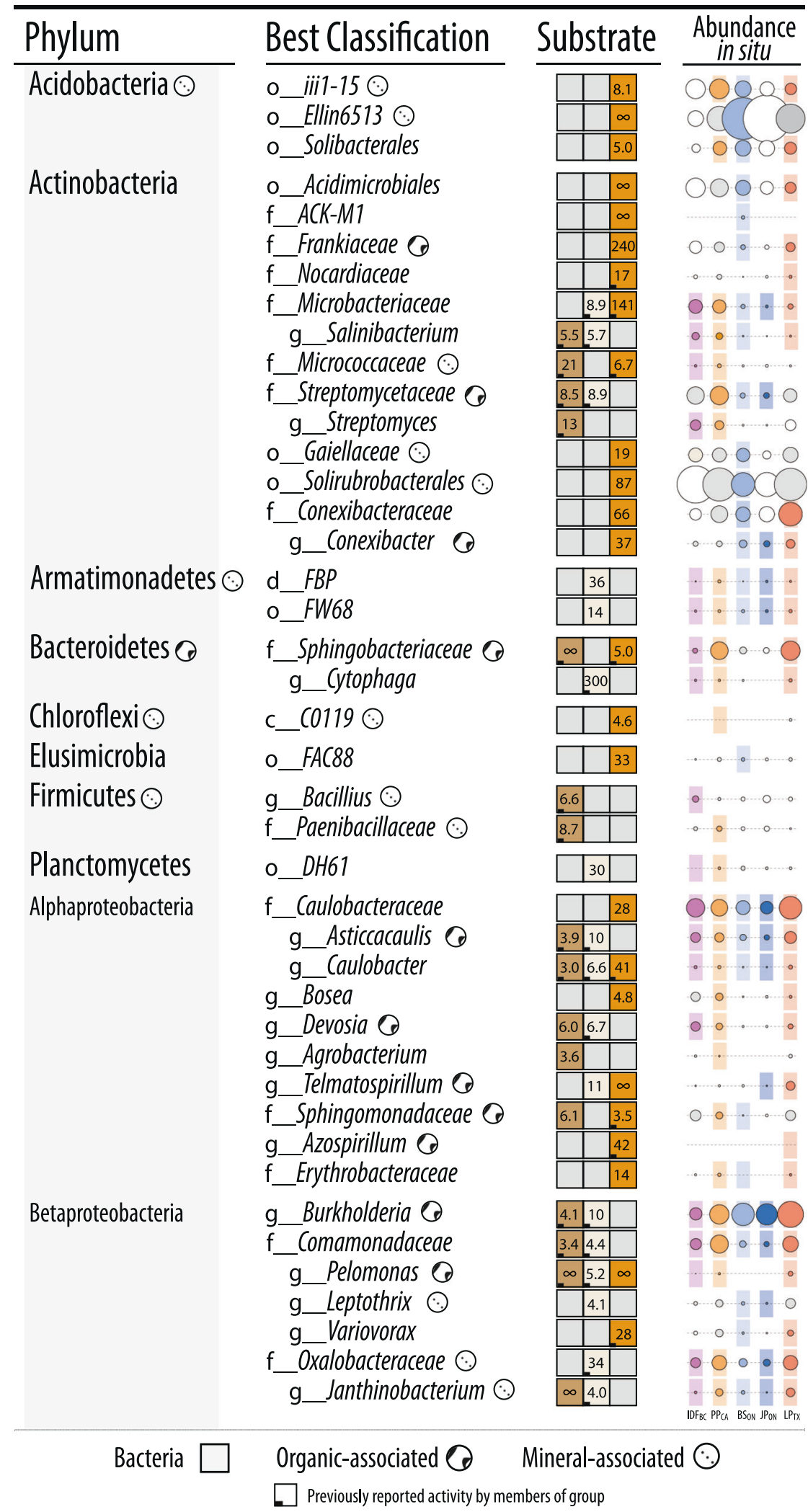

version of the 'nr' NCBI database (downloaded October 2014). MAGs were classified to a specific taxon if $>25 \%$ of contigs were uniformly classified at the genus level. ORF ancestor classification of raw, assembled and MAG data was performed with MEGAN ([53]; v. 5.10.1) based on DIAMOND blastx ([54]; v. 0.7.9) searches against a local 
Fig. 2 (Continued)

\begin{tabular}{|c|c|c|c|}
\hline Phylum & Best Classification & Substrate & $\begin{array}{c}\text { Abundance } \\
\text { in situ }\end{array}$ \\
\hline \multirow[t]{3}{*}{ Deltaproteobacteria } & o_MIZ46 $\odot$ & \begin{tabular}{|l|l}
$\infty$ & \\
\end{tabular} & $\cdots \cdots$ \\
\hline & f_Cystobacteraceae & 20 & \\
\hline & f_Polyangiaceae & 61 & $\cdots 0 \cdots$ \\
\hline \multirow[t]{4}{*}{ Gammaproteobacteria } & g_Cellvibrio & \begin{tabular}{|l|l|}
18 & 6.1 \\
\end{tabular} & 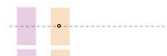 \\
\hline & g_Pseudomonas & & $\cdots 0$. \\
\hline & f_Piscirickettsiaceae $\bigcirc$ & 250 & $\cdots \cdots$ \\
\hline & f_Sinobacteraceae $\odot$ & 16 & $\circ$ \\
\hline \multirow{3}{*}{$\begin{array}{l}\text { TM7@ } \\
\text { (Candid. Saccharibacteria) } \\
\text { Verrucomicrobia }\end{array}$} & c_tM7-3 $\odot$ & 23 & $\cdots \cdots$ \\
\hline & p__verrucomicrobia & 2.0 & $\cdots 000$ \\
\hline & f__Opitutaceae $Q$ & $\triangle 88$ & $\therefore 0.0$ \\
\hline \multirow[t]{13}{*}{ Ascomycota } & g_Pseudogymnoascus & 661 & 000 \\
\hline & g_Botrytis & $\triangle 11$ & 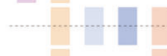 \\
\hline & g_Arthrobotrys Q & 10 & \\
\hline & $\begin{array}{l}f \text { Saccharomycetaceae } \odot \\
\mathrm{q} \text { Verticillium } \bigcirc\end{array}$ & $\angle 12$ & $\ldots$ \\
\hline & g_trichoderma $\bigcirc$ & $\checkmark 15$ & $\ldots .00$ \\
\hline & g_Hypocrea & 4.6 & $\therefore 0.0$ \\
\hline & g_Fusarium Q & 23 & $\cdot \ldots$ \\
\hline & g_Ophiocordyceps & 8.9 & 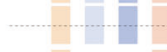 \\
\hline & g_Chaetomium & 46 & 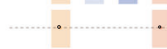 \\
\hline & g_Humicola & 30 & $\ldots \ldots$ \\
\hline & g_ Myceliopthora $Q$ & 454 & 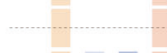 \\
\hline & g_Neurospora $Q$ & 225 & $\ldots+\ldots$ \\
\hline & g_Magnaporthe $Q$ & 37 & $x-2=$ \\
\hline \multirow[t]{7}{*}{ Basidiomycota } & g_Pleurotus & 5.2 & 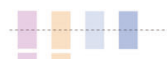 \\
\hline & g_Coprinopsis & 2.8 & $-1--$ \\
\hline & g_Schizophyllum 6 & 2.3 & n- \\
\hline & g_Laccaria & $\triangle 1.6$ & . . . . . \\
\hline & g_Piriformospora & $\triangle 42$ & 남 \\
\hline & g_Trichosporon $\bigcirc$ & 2.4 & $\cdots 0 \cdots$ \\
\hline & g_Cryptococcus $Q$ & 22.4 & 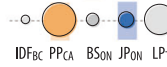 \\
\hline
\end{tabular}

$\begin{array}{lc}\text { Bacteria } \square \text { Fungi } \square & \text { Organic-associated } \\ \text { Forest Sites } & \text { Substrate } \\ \text { British Columbia (IDF) } & \text { Hemicellulose } \\ \text { California (PP) } & \text { Cellulose } \\ \text { Ontario (BS) } & \text { Lignin } \\ \text { Ontario (JP) } & \\ \text { Texas (LP) } & \square \text { Previously reported activity } \\ \text { by members of group }\end{array}$

Mineral-associated $\odot$

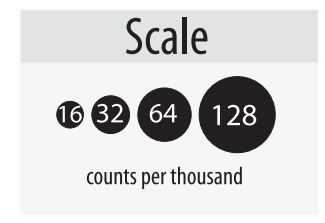

prediction was performed by Prodigal ([55]; v. 2.6.2) and CAZy encoding ORFs were identified based on BLAST searches against a local CAZy database (downloaded 19 August 2015) and hmmscan searches ([56]; HMMER v.3.1b1) using custom hmms for oxidative, lignolytic gene families (see Supplementary Methods) and hmms provided by dbCAN [57]. Contigs containing clusters of three or more genes encoding CAZymes ('CAZy gene clusters') were recovered using a custom approach described in the Supplementary Methods. CAZyme families attributed 


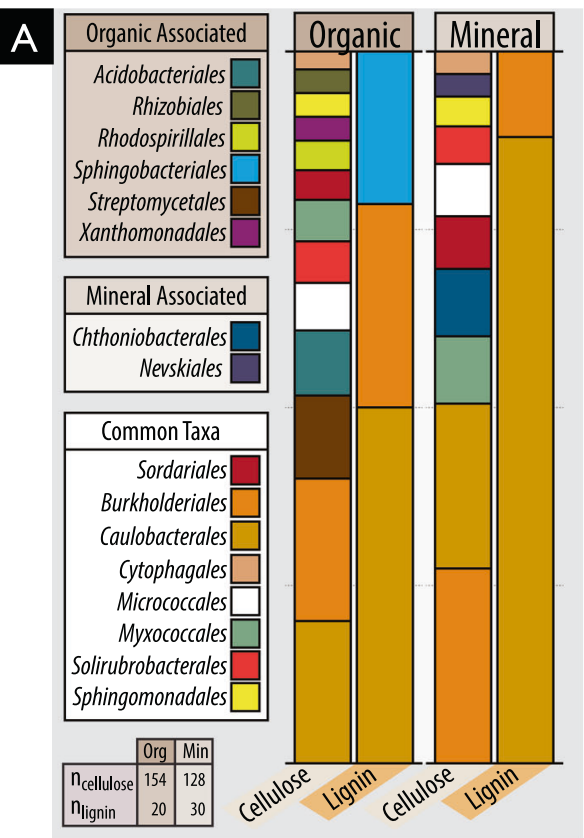

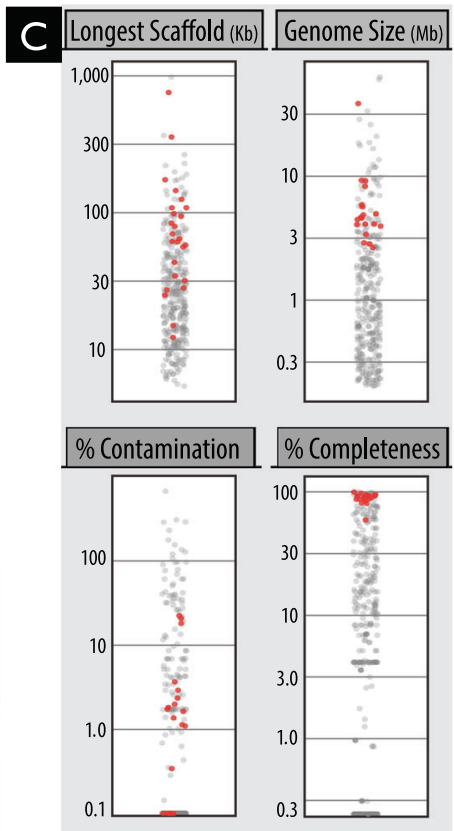

Fig. 3 An overview of the classification and quality of metagenomeassembled genomes (MAGs) recovered from organic and mineral soil layers from ${ }^{13} \mathrm{C}$-cellulose and ${ }^{13} \mathrm{C}$-lignin shotgun metagenomes. (A) Proportion of MAGs classified to various Orders. Taxonomic designations are given to any MAG possessing $>40 \%$ uniformity in the classification of sequence data (normalized to contig length).
(B) Information about the top-quality MAGs based on completeness $(>80 \%)$ and low contamination $(<40 \%)$ based on the completeness or duplication, respectively, in lineage-specific single-copy gene sets. (C) Quality metrics for all MAGs, with top-quality MAGs identified as red points. The complete list and all information on the MAGs is provided in Table S5 xylanase, endoglucanase and ligninase activity can be found in the Supplementary Methods.

Statistics were performed using R v. 3.1.0 [58] with general dependency on the following packages: reshape2, ggplot2, plyr [59-61], Hmisc [62] and phyloseq [63]. Where necessary, P-values were adjusted according to Benjamini and Hochberg [64]. The 'vegan' R-package [65] provided tools to calculate, non-parametric multidimensional scaling (metaMDS) on Bray-Curtis dissimilarities ('vegdist). A combination of DESeq [66] and indicator species analysis (De Cáceres and Legendre 2009) were used to compare control and labeled microcosms to identify OTUs and taxonomic groups that incorporated $13 \mathrm{C}$ from the labeled substrate. An OTU or taxon had to be selected by at least one of these methods and be, on average, 3 -fold more abundant in ${ }^{13} \mathrm{C}$ libraries in at least one geographic region. Random forest classification, implemented in boruta [67], was used to identify taxa or CAZymes predictive of total ${ }^{13} \mathrm{C}$ incorporation into DNA or PLFA. Correlation between features selected by boruta and total ${ }^{13} \mathrm{C}$ were subsequently performed using 'rcorr' from the $\mathrm{R}$ package Hmisc. The relative importance of soil layer, geographic region, total carbon, CAZy composition and community structure in linear models for each substrate was assessed using the $\mathrm{R}$ package relaimpo [68] using the primary and secondary axes of NMDS as measures of community structure and CAZy composition.

\section{Results}

We utilized SIP microcosm-based experiments to investigate the taxonomic identity and catabolic potential of lignocellulolytic populations from coniferous forest soils in five regions across North America. Microcosms contained either organic (top 2-5 cm) or mineral layer soil $(5-20 \mathrm{~cm}$ ) and were amended with either ${ }^{13} \mathrm{C}$-labeled hemicellulose, cellulose or lignin (Fig. 1a). Significant enrichment of ${ }^{13} \mathrm{C}$ in soil DNA extracts (Fig. 1b) and PLFAs, and the recovery of heavy DNA from higher density gradient fractions (Fig. 1c) confirmed the catabolism and assimilation of ${ }^{13} \mathrm{C}$ from substrates. The quantification of total ${ }^{13} \mathrm{C}$ in PLFA and DNA was in close agreement $(r=0.74, p<0.001)$. The successful targeting of lignocellulolytic populations was evident in the strong compositional differences in DNA and PLFA profiles from soils amended with ${ }^{13} \mathrm{C}$-labeled substrates compared to controls. A total of 503 OTUs were enriched in ${ }^{13} \mathrm{C}$ amplicon libraries, enabling the determination of which taxa had the capacity to degrade multiple lignocellulosic (Fig. 2; full list in Table S4). The enrichment of degradative populations was also apparent in shotgun metagenomes, as evidence by the increased proportion of reads comprising the assembly (Figure $\mathrm{S} 2$ ), the assembly quality $\left(\mathrm{N}^{2} 0_{13 \mathrm{C}}=4000\right.$ vs. $\left.\mathrm{N}^{2} 0_{12 \mathrm{C}}=2100 ; t=2.83, p=0.005\right)$, and the recovery of a greater number of MAGs from metagenomes prepared from ${ }^{13} \mathrm{C}$-enriched DNA compared to controls (Fig. 3). The 


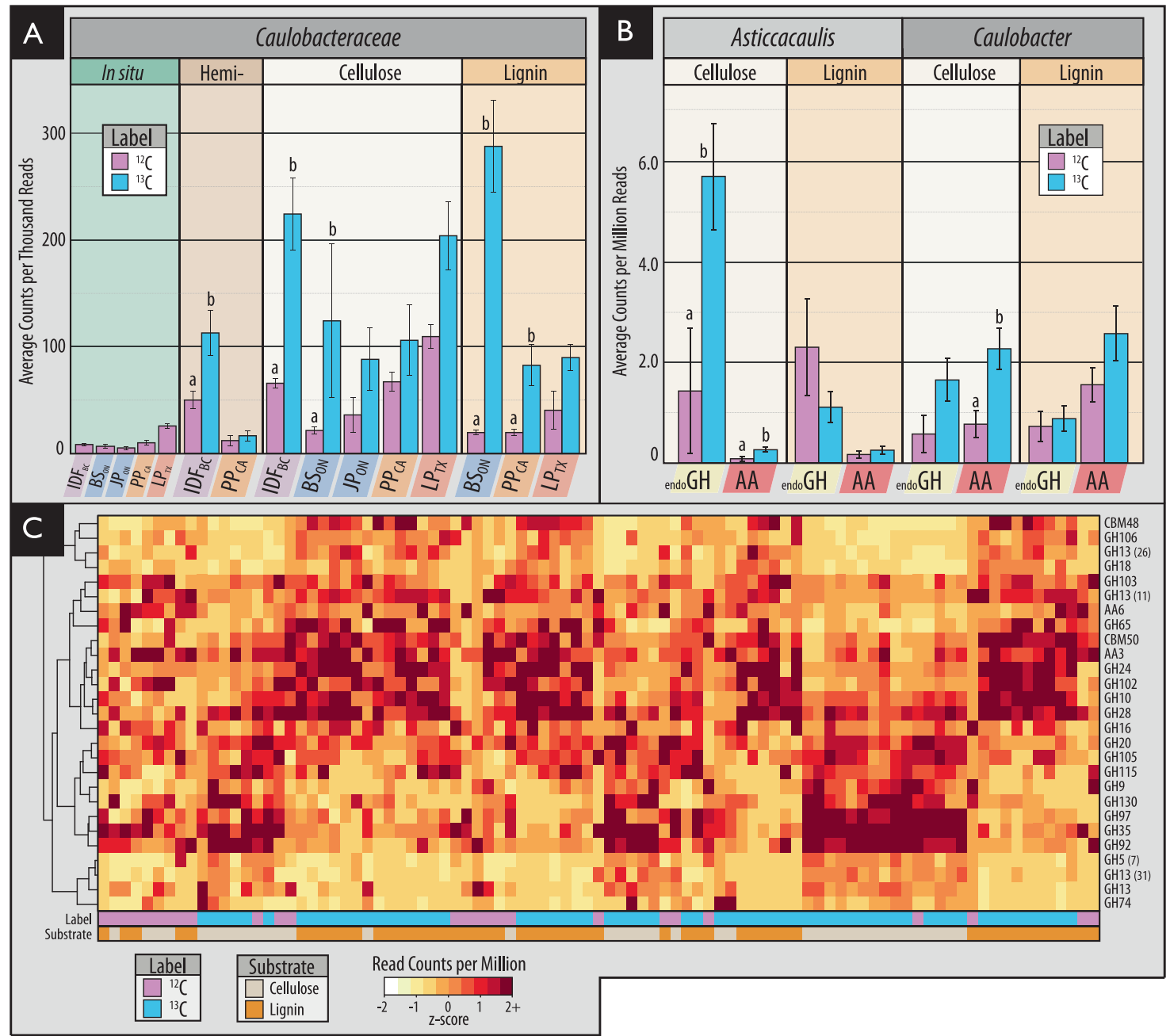

Fig. 4 Characteristics of ${ }^{13} \mathrm{C}$ assimilation by members of Caulobacteraceae evidenced by (A) their enriched relative abundance in ${ }^{13} \mathrm{C}$ amplicon libraries for all three substrates; (B0 differences in the relative abundance of endoglucanase and AA gene families between closely related genera, Asticcacaulis and Caulobacter, and (C) a heatmap profiling CAZy gene content in cellulose and lignin metagenome assemblies. In $(\mathbf{C})$, the $\mathrm{x}$-axis corresponds to individual

high quality of MAGs enabled the characterization of gene content to test our conclusions about individual capacities for catabolizing lignocellulosic polymers.

\section{Identifying degraders of multiple lignocellulosic polymers}

Members of the family Caulobacteraceae and order Burkholderiales dominated ${ }^{13} \mathrm{C}$-enriched DNA pools, comprising between $1-5 \%$ of ${ }^{13} \mathrm{C}$-metagenomes, and were highly represented in our collection of MAGs (Fig. 3). In Burkholderiales, three major families possessed taxa that could degrade one or more substrates: Burkholderiaceae, Comamonadaceae and Oxalobacteraceae (Fig. 2; Figure S3). In Caulobacteraceae, members of the genus Asticcacaulis metagenomes and the y-axis abundant CAZy families. Both axes are clustered according to Bray-Curtis dissimilarity for the full dataset, though only CAZy families with greater than 5 read counts per million were displayed. Statistically supported differences are grouped by lettering (TukeyHSD; $p<0.01$ ). Consult Figure S4 for a complete breakdown of differentially abundant genera in Caulobacteraceae

assimilated ${ }^{13} \mathrm{C}$ from both hemicellulose and cellulose, while members of Caulobacter demonstrated the capacity to assimilate all three substrates (Fig. 4a; full breakdown in Figure S4). Notably, several OTUs belonging to unclassified clades of Caulobacteraceae were highly enriched in ${ }^{13} \mathrm{C}$-DNA pools from lignin (Figure S5) and were significantly more abundant in mineral than organic soils (21.5 vs. 6.0 counts per thousand reads, respectively; $t$-test; $p=$ 0.02). Differences in predisposition for cellulose- versus lignin-catabolism in Asticcacaulis versus Caulobacter, respectively, was evident in the catabolic gene content of metagenome assemblies (Figs. 4b, c).

We anticipated that lignocellulolytic species would commonly degrade more than one of the three lignocellulosic polymers tested, yet most incorporated ${ }^{13} \mathrm{C}$ 


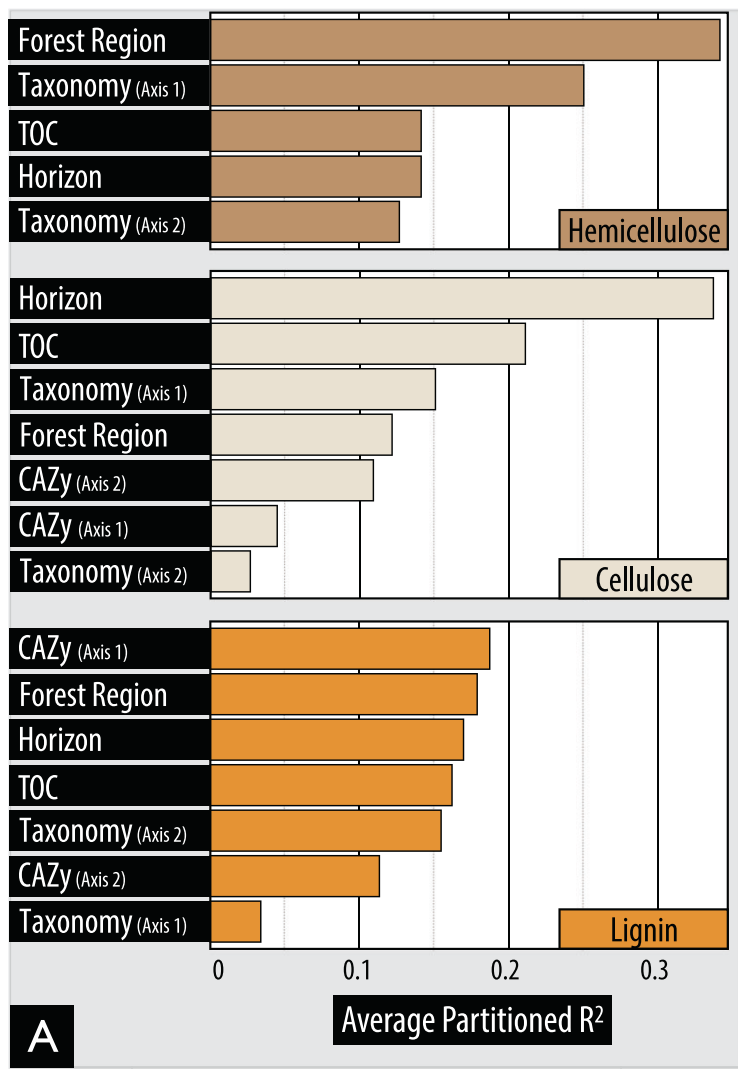

Fig. 5 The influence of environmental and microbial community variables on lignolytic activity. (A) Environmental and community compositional variables which explain the highest proportion of variance in total ${ }^{13} \mathrm{C}$ incorporation into PLFA. Compositional predictors 'taxonomy' and 'CAZy' were based on the separation of samples by the primary and secondary axes of NMDS ordinations. (B0 The

from only one (Fig. 2). No single OTU had increased relative abundance in ${ }^{13} \mathrm{C}$-DNA pools for all three substrates. Only five OTUs were enriched in ${ }^{13} \mathrm{C}$-DNA pools for two substrates and were, in all cases, enriched from ${ }^{13} \mathrm{C}$ lignin and ${ }^{13} \mathrm{C}$-cellulose. These OTUs were classified as Simplicispira (Burkholderiaceae), Aquincola (Comamonadaceae), unclassified Caulobacteraceae and two Sinobacteraceae (Figure S6). The only genera to possess OTUs that collectively incorporated ${ }^{13} \mathrm{C}$ from all three substrates were Pelomonas and Caulobacter. More taxa possessed OTUs that collectively catabolized a combination of hemicellulose and cellulose $(n=7)$ than cellulose and lignin $(n=4)$, or hemicellulose and lignin $(n=3)$. Genera that utilized both hemicellulose and cellulose included Cellvibrio, Janthinobacterium, Cytophaga and Salinibacterium. All fungal taxa enriched in unassembled ${ }^{13} \mathrm{C}$-metagenomes were enriched from cellulose, with the sole exception of a putative member of Saccharomycetaceae from lignin. SIP tended to enrich relatively rare populations, evidenced by the small proportion of OTUs (41/503) shared between ${ }^{13} \mathrm{C}$ -
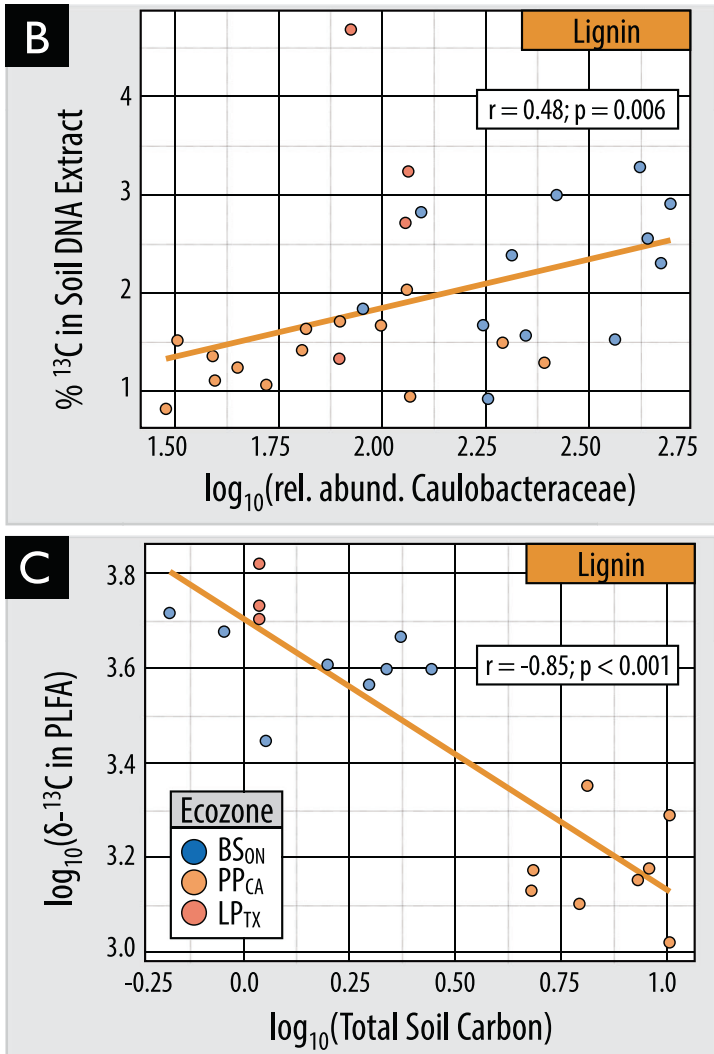

correlation in relative abundance of Caulobacteraceae reads in $16 \mathrm{~S}$ rRNA libraries and ${ }^{13} \mathrm{C}$-enrichment of DNA for lignin. (C) The negative correlation between total ${ }^{13} \mathrm{C}$ incorporation from lignin into PLFA and total soil carbon in mineral soils. $\delta{ }^{-13} \mathrm{C}$ is a measure of the ratio of stable isotopes of carbon relative to Vienna Pee Dee Belemnite

amplicon libraries and unincubated field samples representing in situ relative abundances.

\section{Correlating soil properties with ${ }^{13} \mathrm{C}$-assimilating populations}

Variation in the composition of ${ }^{13} \mathrm{C}$-assimilating bacterial populations was explained most by substrate use (PERMANOVA; $R^{2}=13 \% ; p<0.001$ ), followed by the interaction of geographic region and substrate use $(10 \% ; p<$ $0.001)$, region $(8 \% ; p<0.001)$ and the interaction of substrate and site $(6 \% ; p<0.001$; Table S6). The relative importance of the predictors of ${ }^{13} \mathrm{C}$-incorporation into DNA or PLFA differed for hemicellulose, cellulose and lignindegrading populations (Fig. 5a). However, soil layer, forest region and CAZy content consistently ranked highly followed by taxonomic composition and total soil carbon content. Higher soil organic matter content slowed rates of ${ }^{13} \mathrm{C}$-assimilation, with total carbon and nitrogen negatively correlated with ${ }^{13} \mathrm{C}$ enrichment of PLFAs in 

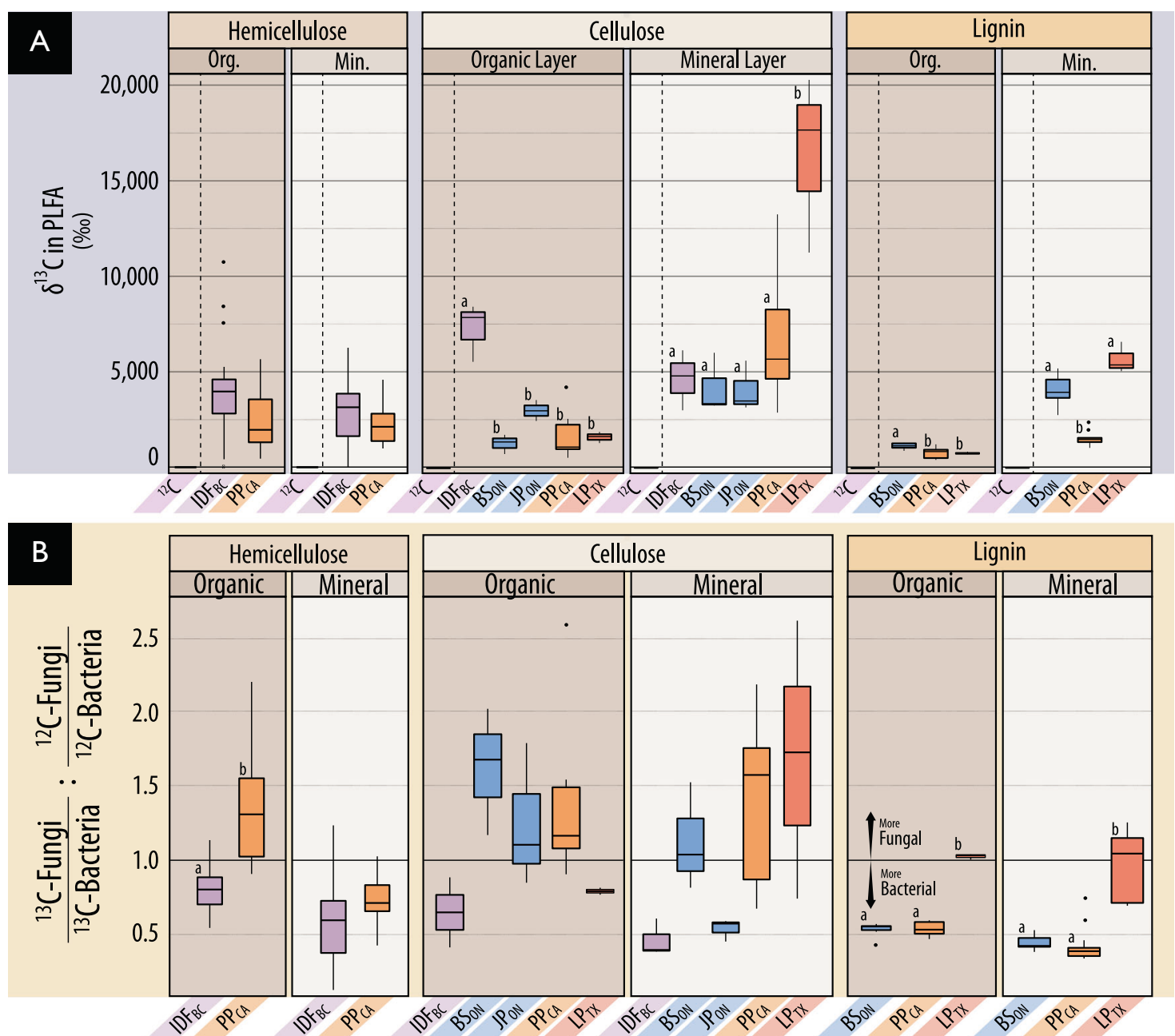

Fig. 6 A comparison of ${ }^{13} \mathrm{C}$ incorporation into microbial biomass by forest region based on (A) $\delta{ }^{-13} \mathrm{C}$ in PLFA, and (B) the relative incorporation into bacterial versus fungal PLFA markers. In (A), PLFAs from microcosms incubated with unlabeled substrates had comparable delta-values to soil $(-25 \%$ ), and low variance, and are distinguished by a dashed line. Statistically supported differences are grouped by lettering (TukeyHSD; $p<0.01$ ). In $(\mathbf{B})$, the ratio represented by the $\mathrm{y}$-axis was designed to normalize ${ }^{13} \mathrm{C}$-enrichment in fungi relative to bacteria $\left({ }^{13} \mathrm{C}_{\text {fungi }}:{ }^{13} \mathrm{C}_{\text {bacteria }}\right)$ to the proportion of preexisting bacterial and fungal biomass $\left({ }^{12} \mathrm{C}_{\text {fungi }}:{ }^{12} \mathrm{C}_{\text {bacteria }}\right)$. Differences in incubation length of microcosms among substrates should be considered when comparing between them. Also, $\delta{ }^{13} \mathrm{C}$ enrichment is weighted against total ${ }^{12} \mathrm{C}$, and thus reflects the total lignocellulolytic activity relative to total biomass which is 3 - to 20 - fold higher in organic layer soils (details in Table S1)

other soils (i.e., $\mathrm{BS}_{\mathrm{ON}}, \mathrm{PP}_{\mathrm{CA}}$ and $\mathrm{LP}_{\mathrm{TX}}$ ). The active lignolytic populations in $\mathrm{BS}_{\mathrm{ON}}$ soils were also distinct from other forest soils, and were comprised of Cystobacteraceae (Deltaproteobacteria), FAC88 (Elusimicrobia, formerly Termite Group 1), Gaiellaceae and Solirubrobacterales (Actinobacteria). Twelve bacterial genera were identified by random forest classification whose relative abundance in ${ }^{13} \mathrm{C}$ amplicon libraries was significantly positively correlated with ${ }^{13} \mathrm{C}$-enrichment of DNA (Table S7). The strongest correlations occurred for Caulobacter (cellulose; $\rho=$ $0.6 ; p_{\text {adj }}<0.001$ ), unclassified Caulobacteraceae (lignin; Fig. 5b), and Janthinobacterium (cellulose; $\rho=0.59 ; p_{\text {adj }}<$ 0.001 ). No fungi were correlated with the ${ }^{13} \mathrm{C}$-enrichment of DNA or PLFA. 


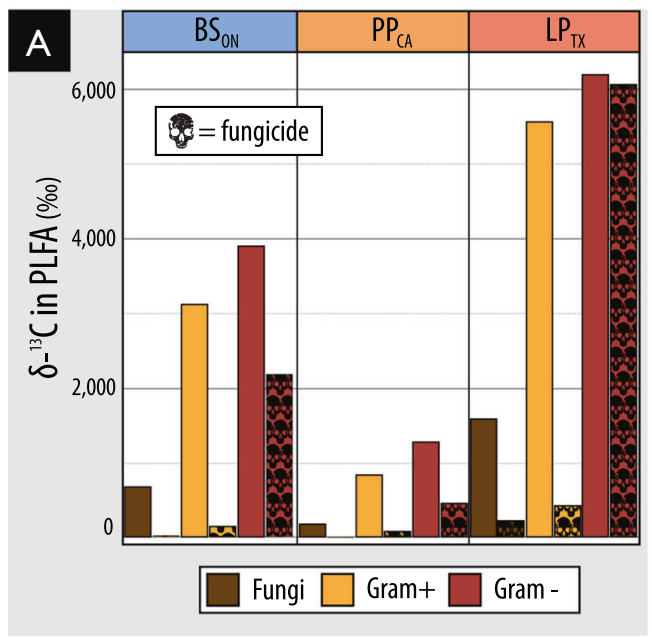

Fig. 7 Impact of fungicide treatment on (a) the total assimilation of ${ }^{13} \mathrm{C}$ from lignin in to PLFA and (A) the relative abundance of taxa in ${ }^{13} \mathrm{C}$-metagenomes. In $(\mathbf{B}), \mathrm{BS}_{\mathrm{ON}}$ was averaged from two replicates. Taxa that commonly occurred in ${ }^{12} \mathrm{C}$-control libraries but were not

\section{Bacterial versus fungal lignocellulolytic activity}

In most microcosms, bacteria were predominantly active in catabolizing and assimilating ${ }^{13} \mathrm{C}$ from substrates and potentially other breakdown products (Fig. 6b; Figure S8). Gram-negative bacteria had the highest $\delta-{ }^{13} \mathrm{C}$ enrichment of PLFAs in $72 \%$ of lignin-amended microcosms, while roughly equal numbers of cellulose- amended microcosms were dominated by gram-negative bacteria or fungi. The total quantity of ${ }^{13} \mathrm{C}$ assimilated into PLFAs $\left(\mu \mathrm{mol} \cdot \mathrm{g}^{-1}\right.$ dry wt soil) did not significantly differ between microcosms with greater bacterial versus fungal assimilation (Wilcoxon test; $W=194, p=0.7)$. Gram-negative and gram-positive bacterial populations dominated the assimilation of hemicellulose in a comparable number of microcosms, $41 \%$ and $39 \%$, respectively, though ${ }^{13} \mathrm{C}$-enrichment was 2 -fold higher when gram-negative bacteria dominated (Wilcoxon test; $W=1261, p<0.001$ ).

Fungicide-treatment greatly reduced assimilation of ${ }^{13} \mathrm{C}$ from lignin into fungal PLFAs, but also into gram-positive bacteria and, to a lesser extent, gram-negative bacteria (Fig. 7a). While overall bacterial activity was decreased by fungicide-treatment, the assimilation of ${ }^{13} \mathrm{C}$ by gramnegative bacteria persisted at relatively high levels (20$50 \%$ of untreated incubations) when zero enrichment of fungal PLFAs had occurred (in $\mathrm{BS}_{\mathrm{ON}}$ and $\mathrm{PP}_{\mathrm{CA}}$ ). The major taxa incorporating ${ }^{13} \mathrm{C}$-lignin in fungicide-treated incubations were distinct from those in untreated ones and were predominantly gram-negative bacteria: Burkholderiaceae and Sphingobacteriaceae (Fig. 7b). Despite the reduction in ${ }^{13} \mathrm{C}$-enrichment of gram-positive PLFAs, the relative abundance of a major lignolytic Actinobacterial family (Nocardiaceae) and Actinobacteria overall (not shown) were

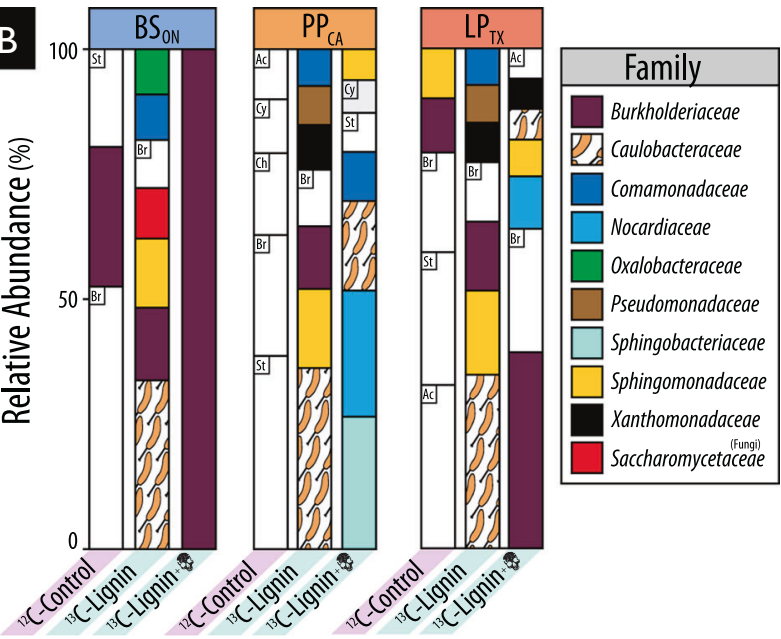

designated as major lignolytic taxa were left uncolored (St: Streptomycetaceae, Br: Bradyrhizobiaceae, Ac: Acidobacteriaceae, Ch: Chitinophagaceae, Cy: Cytophagaceae). Taxa comprising fewer than $0.05 \%$ of total reads are not displayed

increased in ${ }^{13} \mathrm{C}$-metagenomes after fungicide treatment. The impact of fungicide-treatment on the relative abundance of Caulobacteraceae differed by region, with only minor decreases observed in $\mathrm{PP}_{\mathrm{CA}}$ and $\mathrm{LP}_{\mathrm{TX}}$.

\section{CAZy gene content in cellulose and lignin-degraders}

Genes encoding lignin-modifying auxiliary activity (AA) enzymes were approximately three-fold more abundant in ${ }^{13} \mathrm{C}$-lignin versus ${ }^{13} \mathrm{C}$-cellulose metagenomes. Yet, many AA families were also enriched in ${ }^{13} \mathrm{C}$-cellulose versus control metagenomes, which corresponded to an overall increase in reads classified as fungal (Fig. 8). In contrast, the enriched AA gene families in ${ }^{13} \mathrm{C}$-lignin metagenomes (AA3, AA4 and AA6) were largely bacterial in origin. Overall, there was an 18-fold increase in fungal versus bacterial AA reads in ${ }^{13} \mathrm{C}$-cellulose metagenomes compared to a 4-fold increase in bacterial versus fungal AA reads in ${ }^{13} \mathrm{C}$-lignin metagenomes (Mann-Whitney, $W=92, p<$ 0.001).

Genes encoding several oxidative enzymes implicated in the depolymerization of lignin were enriched in ${ }^{13} \mathrm{C}$-lignin metagenomes and were classified to taxa previously identified as assimilating ${ }^{13} \mathrm{C}$ from lignin in amplicon libraries. More specifically, genes encoding laccases (AA1), dyedecolouring peroxidases (DyP) and alcohol oxidases were the most enriched AA gene families. These were predominantly classified to Commamonadaceae, Sphingomonadaceae and Caulobacteraceae (Figure S9a). Nine MAGs contained genes predicted to encode the entire $\beta$-ketoadipate pathway, potentially involved in catabolizing aromatic lignin depolymerization products to central metabolites, and were classified to Burkholderia, Sphingomonas, 
Fig. 8 Differences in proportion of fungal and bacterial encoded auxiliary activity (ligninmodifying) genes in ${ }^{13} \mathrm{C}$ versus ${ }^{12} \mathrm{C}$-metagenomes. Bubbles are coloured according to domain of life and scaled to the total read counts per million. The top three most enriched taxa, at least 3fold more abundant in ${ }^{13} \mathrm{C}$ libraries, are displayed and coloured according to domain of life. The fold-change of enrichment for each taxa is provided in brackets

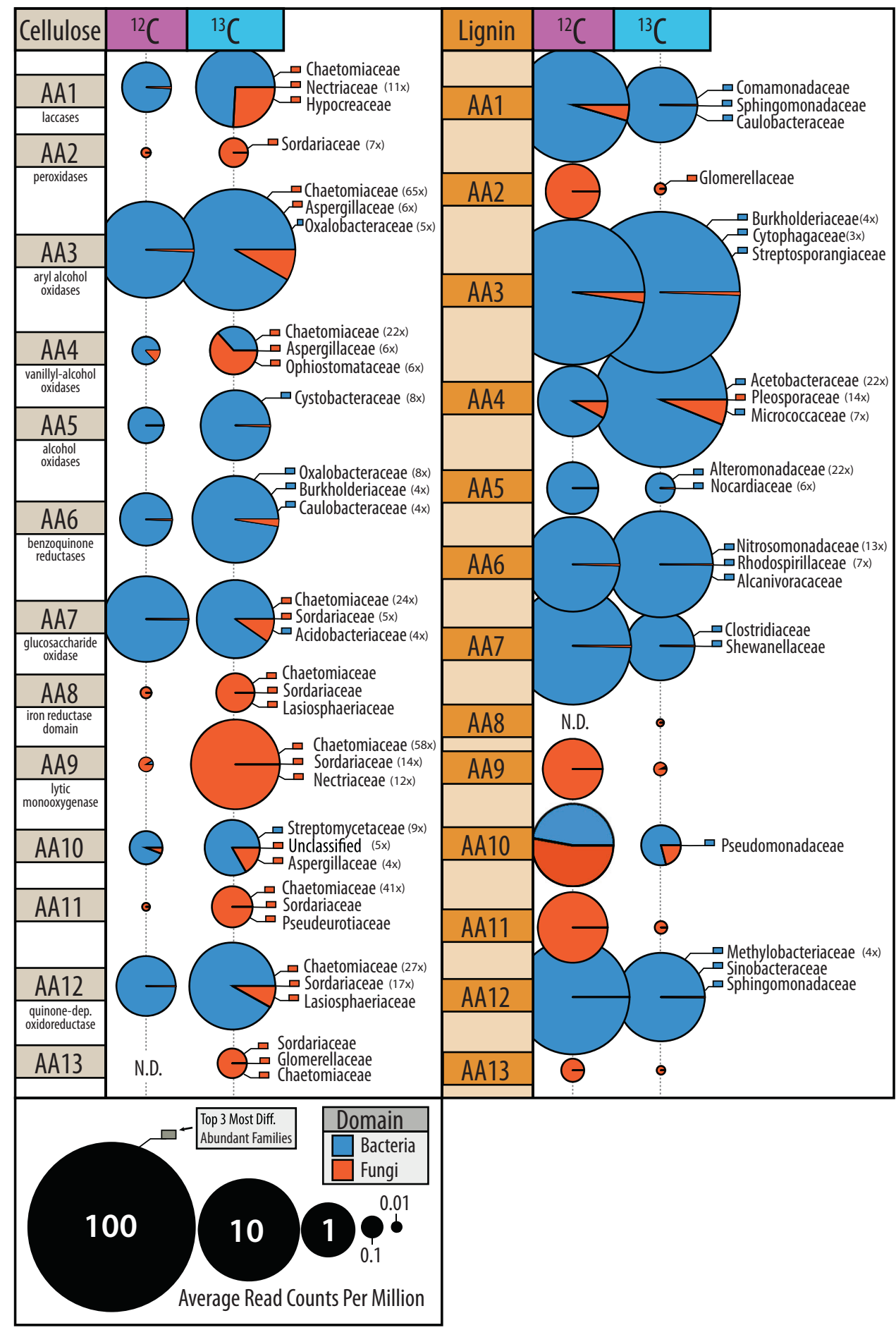

Caulobacter and Sorangium. Aryl alcohol oxidase genes were the most significantly correlated $\left(\rho>0.3\right.$ and $p_{\text {adj }}<$ 0.01 ) with total ${ }^{13} \mathrm{C}$-assimilation from lignin into PLFA.

${ }^{13} \mathrm{C}$-cellulose metagenomes were highly enriched in glycosyl hydrolase gene families (GHs). Approximately $37 \%$ of CAZy gene clusters (groups of 3 or more GHs) from ${ }^{13} \mathrm{C}$-cellulose metagenomes contained carbohydrate-binding module (CBM) genes and $4 \%$ of these also contained an endoglucanase gene. In comparison, only $22 \%$ of clusters in ${ }^{13} \mathrm{C}$-lignin metagenomes contained a CBM gene, and none of these contained endoglucanase genes. Thirty-three percent of endoglucanase gene-containing clusters contained a CBM, and were mostly classified to Asticcacaulis, Sorangium and Chthoniobacter (Figure S9b). Actinomycetales had the greatest diversity of endoglucanase gene families in CAZy gene clusters, while fungi predominantly had 
endoglucanase genes belonging to $\mathrm{GH} 7$ and $\mathrm{GH} 9$ families (Figure S9c). Few endoglucanase or GH gene families were correlated with cellulolytic activity (Table S7). Four MAGs contained CAZy gene clusters encoding enzymes putatively catabolizing all three substrates (i.e., xylanases, endoglucanases and ligninases) and were classified as Chaetomium (fungi), Caulobacter, Chthoniobacter and Sphingobium (Table S8).

\section{Discussion}

We failed to find support for our initial hypothesis that individual species would degrade multiple components of lignocellulose. Instead, we identified a diverse array of taxa assimilating ${ }^{13} \mathrm{C}$ from three major lignocellulosic polymers, demonstrating the degree of specialization in decomposer populations. While approximately one third of taxa enriched in ${ }^{13} \mathrm{C}$-DNA pools possessed members that could collectively degrade more than one substrate, and, though a handful of MAGs encoded a putative suite of catabolic enzymes, none of the individual bacterial OTUs (at a 99\% similarity threshold) were definitively enriched from all three substrates. Even closely related taxa, like Caulobacter and Asticcacaulis, exhibited differences in their levels of enrichment on cellulose and lignin and in CAZy gene content. In contrast, the multisubstrate degradative capacity of fungi was evident in the increased relative abundances of genes encoding both delignifying (peroxidases) and cellulolytic enzymes in ${ }^{13} \mathrm{C}$-DNA pools. The recovery of a Myceliophthora MAG from ${ }^{13} \mathrm{C}$-metagenomes was consistent with its known capability for complete lignocellulose decomposition [69, 70]. Therefore, our findings suggest that complementation among functional guilds may be necessary for decomposition of lignocellulose by bacteria and not necessarily fungi. One caveat is the possibility that our method was biased towards identifying single substrate utilizing bacteria. The activity of multi-substrate users may have been masked by populations that grew faster on individual substrates, particularly the relatively labile hemicellulose, as was observed in other SIP experiments [71]. At the very least, our study demonstrates the decomposition of lignocellulosic polymers can commonly occur via a division of labour among specialized taxa.

The substantial assimilation of carbon from our model lignin substrate by bacteria supports our hypothesis that bacteria contribute significantly to degradation of native forms of lignin in situ. Bacterial activity was particularly evident in deeper mineral layers of forest soil, suggesting that lignin decomposition can occur throughout the soil column. Interestingly, the most novel lignin-degraders from mineral soils belong to uncultured clades of
Caulobacteraceae, Acidobacteria, Solirubrobacterales, Elusimicrobia, Nevskiales, and Cystobacteraceae. The low activity of fungal lignin degraders in our microcosms was unlikely due to unmet nutritional or environmental conditions, since metabolically competent taxa like Myceliophthora [69, 70] assimilated carbon from cellulose under the same conditions. One possible explanation is that fungi were involved in lignin-degradation but did not metabolize degradation products to become sufficiently labeled, perhaps because of bacterial cross-feeding, evident in the inhibitory effect of fungicide on lignin incorporation by bacteria. Indeed, the results from the fungicide-treatments indicated significant interactions occurred between bacteria and fungi in lignin degradation. However, fungi were not essential for bacterial lignin degradation, given the persistent and substantial incorporation of ${ }^{13} \mathrm{C}$-lignin by bacteria in fungicide-treated soils. This study provides strong evidence for the capacity of bacteria to degrade lignin, highlighting the need for further characterization of their activity and ecology in soil.

The substantial number of taxa identified by SIP with previously reported lignocellulolytic activity was testament to the success of previous culturing-based efforts to characterize soil decomposers and a validation of our SIP approach. Approximately $72 \%$ (14/19) of hemicellulolytic taxa and $74 \%(31 / 42)$ of cellulolytic taxa were previously reported to degrade the corresponding substrate in vitro. Far fewer lignolytic taxa $(28 \%, 8 / 29)$ had previously reported degradative activity, likely due to less frequent and formalized testing of lignin degradation. However, there was considerable agreement in the bacterial genera we identified and those identified in other culture-independent studies of lignin-degraders in forest soil, such as Caulobacter, Sphingomonas, Sphingobacterium, Nocardia, Telmatospirillum and Azospirillum [13, 22, 72]. A lower proportion of lignin-degrading taxa associated with mineral layer soil (5/ 16) had previously reported activity compared to those associated with the organic layer (8/12), suggesting the former may be more difficult to culture or were less frequently targeted for study.

Many of the novel cellulolytic groups we identified belong to cultivation-resistant phyla, Planctomycetes, Verrucomicrobia, Chloroflexi and Armatimonadetes (formerly OP10), which commonly predominate soil communities [73, 74]. Each of these phyla possesses at least one isolate capable of degrading cellulose [75-78] and have been designated cellulolytic in other SIP-cellulose experiments [28, 71, 79, 80]. Notably, all contigs that contained clusters of ten or more CAZymes (27 contigs), from ${ }^{13} \mathrm{C}$-cellulose metagenomes, were classified to taxa from the aforementioned groups and contained both CBMs (26/27) and endoglucanases (20/27). These findings supported our assertion that the richness of described lignocellulolytic taxa is underestimated in soils, 
which limits our understanding of the ecology of decomposition and may afford new types of biocatalysts for processing lignocellulosic biomass.

The widespread capacity among members of Caulobacteraceae to degrade the three components of lignocellulose was unexpected, yet consistent with reports of their enrichment on decaying wood [81, 82] and during early stages of litter decomposition [83]. Caulobacter were first isolated from cellulose-amended lake-water [84], but are primarily known as oligotrophic, aquatic organisms [85]. Their role in degradation of plant carbohydrates was first postulated based on the analysis of the $C$. crescentus genome [86] and subsequently demonstrated by growth on cellulose, xylose and vanillate [87-90]. Although we provide the first evidence for the role of Caulobacteraceae in degrading all three polymers of lignocellulose, several surveys of forest soils report enrichment of Caulobacter or Asticcacaulis in samples amended with cellulose [80, 91, 71] or lignin $[13,22]$. The role of Caulobacteraceae in decomposition in forest soils may prove significant, given their relatively high abundance (0.5-2.5\% of total libraries) and their capacity to adhere to insoluble polymers, like lignocellulose.

The taxonomy and catabolic capacity of lignocellulose degraders were moderately associated with variation in the total lignocellulolytic activity. The influence of compositional differences between soil layers was, in certain cases, overshadowed by the strong negative correlation between organic matter and ${ }^{13} \mathrm{C}$ enrichment. Yet, in regression modeling, CAZy gene content and community composition had equivalent or greater explanatory power than other predictors. The abundances of several prominent lignocellulolytic taxa were significantly correlated with higher ${ }^{13} \mathrm{C}$ assimilation, demonstrating that certain taxa play more significant roles, at least under conditions we tested. Strongly oxidative bacterial enzymes commonly studied in relation to lignin-degradation, such as DyP-type peroxidases and laccases [92-94], were less predictive of lignolytic activity than aryl alcohol oxidases, suggesting a greater role of the latter class of enzymes in bacterial lignindegradation. Overall, fewer endoglucanase genes were predictive of ${ }^{13} \mathrm{C}$-assimilation compared to $\mathrm{AA}$ gene families. This difference suggests either the existence of a greater diversity of endoglucanases, minimizing the explanatory power of any single gene, or a narrower activity range of AA families with a correspondingly higher relevance to lignolytic activity. This result agrees with the finding that the composition of decomposer communities had increased explanatory power for the rate of litter decomposition during later stages when greater proportions of lignin remained (Cleveland et al. 2014).

The comprehensive study of all three major lignocellulosic polymers enabled us to examine the cooccurrence of lignocellulolytic traits, addressing several knowledge gaps in this area. The results indicated unexpected specialization among bacterial populations for degradation of individual lignocellulosic polymers and revealed several novel lignocellulolytic taxa, highlighting current limits to our knowledge of decomposition. This research supports the view that bacterial decomposition of oligomeric lignin is a ubiquitous soil process, with the potential to occur in deeper soil layers following early stages of litter decomposition. As hypothesized, variation in community composition was found to constrain lignocellulolytic activity across various forest types and soil layers in North America. The relationship between these communities and process rates should receive continuing study to refine our understanding of soil carbon stabilization and terrestrial carbon cycling models. Furthermore, the large number of degradative gene clusters from uncultivated lignocellulolytic taxa represent a trove of potentially novel enzymes for biotechnological applications.

Acknowledgements This study was supported by a Large Scale Applied Research Project (162MIC) funded by Genome Canada and Genome BC. RCW was supported by a NSERC graduate scholarship and UBC Four Year Fellowship.

\section{Compliance with ethical standards}

Conflict of interest The authors declare that they have no conflict of interest.

Open Access This article is licensed under a Creative Commons Attribution 4.0 International License, which permits use, sharing, adaptation, distribution and reproduction in any medium or format, as long as you give appropriate credit to the original author(s) and the source, provide a link to the Creative Commons license, and indicate if changes were made. The images or other third party material in this article are included in the article's Creative Commons license, unless indicated otherwise in a credit line to the material. If material is not included in the article's Creative Commons license and your intended use is not permitted by statutory regulation or exceeds the permitted use, you will need to obtain permission directly from the copyright holder. To view a copy of this license, visit http://creativecommons. org/licenses/by/4.0/.

\section{References}

1. Myneni RB, Dong J, Tucker CJ, Kaufmann RK, Liski J, Zhou L, et al. A large carbon sink in the woody biomass of Northern forests. PNAS. 2001;98:14784-9.

2. Strickland MS, Rousk J. Considering fungal: bacterial dominance in soils-methods, controls, and ecosystem implications. Soil Biol Biochem. 2010;42:1385-95.

3. Cleveland CC, Reed SC, Keller AB, Nemergut DR, O'Neill SP, Ostertag $\mathrm{R}$, et al. Litter quality versus soil microbial community controls over decomposition: A quantitative analysis. Oecologia 2014;174:283-294.

4. Allison SD. A trait-based approach for modelling microbial litter decomposition. Ecol Lett. 2012;15:1058-70. 
5. Wieder WR, Grandy AS, Kallenbach CM, Taylor PG, Bonan GB. Representing life in the Earth system with soil microbial functional traits in the MIMICS model. Geosci Model Dev. 2015;8:1789-808.

6. Melillo JM, Aber JD, Linkins AE, Ricca A, Fry B, Nadelhoffer KJ. Carbon and nitrogen dynamics along the decay continuum: Plant litter to soil organic matter. Ecol Arab L - Perspect Challenges 1989;198:53-62.

7. Cotrufo MF, Soong JL, Horton AJ, Campbell EE, Haddix ML, Wall DH, et al. Formation of soil organic matter via biochemical and physical pathways of litter mass loss. Nat Geosci 2015;8: 776-9.

8. von Lützow M, Kögel-Knabner I, Ekschmitt K, Flessa H, Guggenberger G, Matzner E, et al. SOM fractionation methods: Relevance to functional pools and to stabilization mechanisms. Soil Biol Biochem 2007;39:2183-207.

9. Lehmann J, Kleber M. The contentious nature of soil organic matter. Nature 2015;528:60-8.

10. Klotzbücher T, Kaiser K, Guggenberger G, Gatzek C, Kalbitz K. A new conceptual model for the fate of lignin in decomposing plant litter. Ecology 2011;92:1052-62.

11. Ekschmitt K, Kandeler E, Poll C, Brune A, Buscot F, Friedrich M, et al. Soil-carbon preservation through habitat constraints and biological limitations on decomposer activity. J Plant Nutr Soil Sci 2008;171:27-35.

12. Benner R, Newell SY, Maccubbin AE, Hodson RE. Relative contributions of bacteria and fungi to rates of degradation of lignocellulosic detritus in salt-marsh sediments. Appl Environ Microbiol 1984;48:36-40.

13. DeAngelis KM, Allgaier M, Chavarria Y, Fortney JL, Hugenholtz P, Simmons B. et al. Characterization of trapped lignin-degrading microbes in tropical forest soil. PLoS ONE. 2011;6:e19306

14. Hall SJ, Silver WL, Timokhin VI, Hammel KE. Lignin decomposition is sustained under fluctuating redox conditions in humid tropical forest soils. Glob Change Biol. 2015;21:2818-28.

15. Brown ME, Barros $\mathrm{T}$, Chang MC. Identification and characterization of a multifunctional dye peroxidase from a lignin-reactive bacterium. ACS Chem Biol. 2012;7:2074-81.

16. Crawford DL. Lignocellulose decomposition by selected Streptomyces strains. Appl Environ Microbiol. 1978;35:1041-5.

17. Davis JR, Goodwin L, Teshima H, Detter C, Tapia R, Han C, et al. Genome sequence of Streptomyces viridosporus strain T7A ATCC 39115, a lignin-degrading Actinomycete. Genome Announc. 2013;1:e00416-00413.

18. DeAngelisb KM, D'Haeseleer P, Chivian D, Fortney JL, Khudyakov J, Simmons B, et al. Complete genome sequence of Enterobacter lignolyticus SCF1. Stand Genom Sci. 2011;5:69-85.

19. Masai E, Katayama Y, Fukuda M. Genetic and biochemical investigations on bacterial catabolic pathways for lignin-derived aromatic compounds. Biosci Biotechnol Biochem. 2007;71: $1-15$.

20. Rashid GM, Taylor CR, Liu Y, Zhang X, Rea D, Fulop V, et al. Identification of manganese superoxide dismutase from Sphingobacterium $s p$. T2 as a novel bacterial enzyme for lignin oxidation. ACS Chem Biol. 2015;10:2286-94.

21. Taylor CR, Hardiman EM, Ahmad M, Sainsbury PD, Norris PR, Bugg TDH. Isolation of bacterial strains able to metabolize lignin from screening of environmental samples. J Appl Microbiol. 2012;113:521-30.

22. Pold G, Melillo JM, DeAngelis KM. Two decades of warming increases diversity of a potentially lignolytic bacterial community. Front Microbiol. 2015;6:480.

23. Eastwood DC, Floudas D, Binder M, Majcherczyk A, Schneider $\mathrm{P}$, Aerts A, et al. The plant cell wall-decomposing machinery underlies the functional diversity of forest fungi. Science (80-) 2011;333:762-5.
24. Ding SY, Liu YS, Zeng Y, Himmel ME, Baker JO, Bayer EA. How does plant cell wall nanoscale architecture correlate with enzymatic digestibility? Science. 2012;338:1055-60.

25. Zeng Y, Zhao S, Yang S, Ding SY. Lignin plays a negative role in the biochemical process for producing lignocellulosic biofuels. Curr Opin Biotech. 2014;27:38-45.

26. Větrovský T, Steffen KT, Baldrian P. Potential of cometabolic transformation of polysaccharides and lignin in lignocellulose by soil actinobacteria. PLoS ONE. 2014;9:e89108.

27. Medie FM, Davies GJ, Drancourt M, Henrissat B. Genome analyses highlight the different biological roles of cellulases. Nat Rev Microbiol. 2012;10:227-34.

28. Wilhelm RC, Cardenas E, Leung H, Szeitz A, Jensen LD, Mohn WW. Long-term enrichment of stress-tolerant cellulolytic soil populations following timber harvesting evidenced by multi-omic stable isotope probing. Front Microbiol. 2017;8:537.

29. Morris SA, Radajweski S, Willison TW, Murrel JC. Identification of the functionally active methanotroph population in a peat soil microcosm by stable-isotope probing. Appl Environ Microbiol. 2002;68:1446-53.

30. Berlemont R, Martiny AC. Phylogenetic distribution of potential cellulases in bacteria. Appl Environ Microbiol. 2013;79:1545-54.

31. Wilhelm RC, Cardenas E, Maas K, Leung H, McNeil L, Berch S, et al. Biogeography and organic matter removal shape long-term effects of timber harvesting on forest soil microbial communities. ISME J. 2017;11:2552-68.

32. Wilhelm RC, Cardenas E, Hahn AS, Leung H, Maas K, Hartmann $\mathrm{M}$, et al. A multi-omic survey of forest soil microbial communities more than a decade after timber harvesting. Sci Data. 2017;4:170092.

33. Leung HT, Maas KR, Wilhelm RC, Mohn WW. Long-term effects of timber harvesting on hemicellulolytic microbial populations in coniferous forest soils. ISME J. 2016;10:363-75.

34. Youngblut N, Buckley DH. Intra-genomic variation in $\mathrm{G}+\mathrm{C}$ content and its implications for DNA stable isotope probing. Env Microbiol. 2015;6:767-75.

35. Kirk TK, Brunow G. Synthetic ${ }^{14} \mathrm{C}$-labeled lignins. In: Methods in enzymology. (eds Colowick SP, Kaplan NO) Vol. 161;65-73 (Academic Press. Cambridge, MA, 1988).

36. Wilhelm RC, Szeitz S, Klassen TL, Mohn WW. Sensitive, efficient quantitation of ${ }^{13} \mathrm{C}$-enriched nucleic acids via ultrahighperformance liquid chromatography-tandem mass spectrometry for applications in stable isotope probing. Appl Environ Microbiol. 2014;80:7206-11.

37. Bligh EG, Dyer WJ. A rapid method of total lipid extraction and purification. Can J Biochem Physiol. 1959;37:911-7.

38. Churchland C, Grayston SJ, Bengtson P. Spatial variability of soil fungal and bacterial abundance: consequences for carbon turnover along a transition from a forested to clear-cut site. Soil Biol Biochem. 2013;63:5-13.

39. Neufeld JD, Vohra J, Dumont MG, Leuders T, Manefield M, Friedrich, et al. DNA stable-isotope probing. Nat Protoc. 2007;2:860-6.

40. Hartmann M, Howes CG, VanInsberghe D, Yu H, Bachar D, Christen R, et al. Significant and persistent impact of timber harvesting on soil microbial communities in Northern coniferous forests. ISME J. 2012;6:2199-218.

41. Wilhelm RC. Deciphering decomposition and the effects of disturbance in forest soil microbial communities with metagenomics and stable isotope probing. Ph.D. thesis. University of British Columbia; 2016.

42. Schloss PD, Westcott SL, Ryabin T, Hall JR, Hartmann M, Hollister EB, et al. Introducing mothur: open-source, platformindependent, community-supported software for describing and comparing microbial communities. Appl Environ Microbiol. 2009;75:7537-41. 
43. Wang Q, Garrity GM, Tiedje JM, Cole JR. Naive Bayesian classifier for rapid assignment of rRNA sequences into the new bacterial taxonomy. Appl Environ Microbiol. 2007;73: 5261-7.

44. Pruesse E, Quast C, Knittel K, Fuchs BM, Ludwig W, Peplies J, et al. SILVA: a comprehensive online resource for quality checked and aligned ribosomal RNA sequence data compatible with ARB. Nucl Acids Res. 2007;35:7188-96.

45. Westram R, Bader K, Prüsse E, Kumar Y, Meier H, Glöckner FO, et al. ARB: a software environment for sequence data. In: Handbook of molecular microbial ecology I: metagenomics and complementary approaches. 399-406 (John Wiley \& Sons, Hoboken, NJ, 2011)

46. Bolger AM, Lohse M, Usadel B. Trimmomatic: a flexible trimmer for illumina sequence data. Bioinformatics. 2014;30: 2114-20.

47. Gordon A, Hannon GJ. Fastx-toolkit. Computer program distributed by the author. 2010. http://hannonlab.cshl.edu/fastx toolkit/index.html. Accessed Nov. 2015.

48. Boisvert S, Raymond F, Godzaridis É, Laviolette F, Corbeil J. Ray Meta: scalable de novo metagenome assembly and profiling. Genome Biol. 2012;13:R122.

49. Li D, Liu CM, Luo R, Sadakane K, Lam TW. MEGAHIT: an ultra-fast single-node solution for large and complex metagenomics assembly via succinct de Bruijn graph. Bioinformatics. 2015;31:1674-6.

50. Kang DD, Froula J, Egan R, Wang Z. MetaBAT, an efficient tool for accurately reconstructing single genomes from complex microbial communities. PeerJ. 2015;3:e1165.

51. Langmead B, Salzberg SL. Fast gapped-read alignment with Bowtie 2. Nat Methods. 2012;9:357-9.

52. Parks D, Imelfort M, Skennerton CT, Hugenholtz P, Tyson G. CheckM: assessing the quality of microbial genomes recovered from isolates, single cells, and metagenomes. Genome Res. 2015;25:1043-55.

53. Huson DH, Auch AF, Qi J, Schuster SC. MEGAN analysis of metagenomic data. Genome Res. 2007;17:377-86.

54. Buchfink B, Xie C, Huson DH. Fast and sensitive protein alignment using DIAMOND. Nat Methods. 2015;12:59-60.

55. Hyatt D, Chen GL, LoCascio PF, Land ML, Larimer FW, Hauser LJ. Prodigal: prokaryotic gene recognition and translation initiation site identification. BMC Bioinforma. 2010;11:119.

56. Finn RD, Clements J, Eddy S. HMMER web server: interactive sequence similarity searching. Nucl Acids Res. 2011;39:W29-37.

57. Yin Y, Mao X, Yan J, Chen X, Mao F, Xu Y. dbCAN: a web resource for automated carbohydrate-active enzyme annotation. Nucl Acids Res. 2012;40:W445-51.

58. $\mathrm{R}$ Core Team. R: a language and environment for statistical computing. Vienna, Austria: R Foundation for Statistical Computing; 2015.

59. Wickham H. Reshaping data with the reshape package. J Stat Soft. 2007;21:1-20.

60. Wickham H. The split-apply-combine strategy for data analysis. J Stat Soft. 2011;40:1-29.

61. Wickham H. Elegant graphics for data analysis.. 2009. New York: Springer-Verlag; 2009.

62. Harrell FE, Dupont C. Hmisc: Harrell miscellaneous. R package version 3.17-1. 2015. Accessed on 12 December 2015. https:// CRAN.R-project.org/package $=$ Hmisc

63. McMurdie PJ, Holmes S. phyloseq: an R package for reproducible interactive analysis and graphics of microbiome census data. PLoS ONE. 2014;8:e61217.

64. Benjamini Y, Hochberg Y. Controlling the false discovery rate: a practical and powerful approach to multiple testing. J R Stat Soc B Met. 1995;Series B:289-300.
65. Oksanen J, Blanchet FG, Kindt R, Legendre P, Minchin PR, O'Hara RB, et al. Vegan: community ecology package. R package version 2.3-1. 2015. http://CRAN.R-project.org/package=vegan

66. Anders S, Huber W. Differential expression analysis for sequence count data. Genome Biol. 2010;11:R106.

67. Kursa MB, Rudnicki WR. Feature selection with the boruta package. J Stat Softw. 2010;36:1-13.

68. Grömping U. Relative importance for linear regression in R: the package relaimpo. J Stat Softw. 2006;17:1-27.

69. Li K, Xu F, Eriksson KE. Comparison of fungal laccases and redox mediators in oxidation of a nonphenolic lignin model compound. Appl Environ Microbiol. 1999;65:2654-60.

70. Babot ED, Rico A, Rencoret J, Kalum L, Lund H, Romero J, et al. Towards industrially-feasible delignification and pitch removal by treating paper pulp with Myceliophthora thermophila laccase and a phenolic mediator. Biores Technol. 2011;102:6717-22.

71. Pepe-Ranney C, Campbell AN, Koechli CN, Berthrong S, Buckley DH. Unearthing the ecology of soil microorganisms using a high-resolution DNA-SIP approach to explore cellulose and xylose metabolism in soil. Front Microbiol. 2016;7:703.

72. Woo HL, Hazen TC, Simmons BA, DeAngelis KM. Enzyme activities of aerobic lignocellulolytic bacteria isolated from wet tropical forest soils. Syst Appl Microbiol. 2014;37:60-7.

73. Youssef $\mathrm{NH}$, Elshahed MS. Diversity rankings among bacterial lineages in soil. ISME J 2009;3:305-13.

74. Bergmann GT, Bates ST, Eilers KG, Lauber CL, Caporaso JG, Walters WA, et al. The under-recognized dominance of Verrucomicrobia in soil bacterial communities. Soil Biol Biochem 2011;43:1450-5.

75. Sangwan P, Chen X, Hugenholtz P, Janssen PH. Chthoniobacter flavus gen. nov., sp. nov., the First Pure-Culture Representative of Subdivision Two, Spartobacteria classis nov., of the Phylum Verrucomicrobia. Appl Environ Microbiol 2004; 70: 5875-81.

76. Lladó S, Benada O, Cajthaml T, Baldrian P, Garcia-Fraile P. Silvibacterium bohemicum gen. nov. sp. nov., an acidobacterium isolated from coniferous soil in the Bohemian forest national park. Syst Appl Microbiol. 2015;39:14-9.

77. Dedysh SN, Kulichevskaya IS. Planctomycetes: Cell Structure, Origins and Biology. 2013;125-39.

78. Lee KCY, Morgan XC, Dunfield PF, Tamas I, McDonald IR, Stott MB. Genomic analysis of Chthonomonas calidirosea, the first sequenced isolate of the phylum Armatimonadetes. ISME J 2014;8:1522-33.

79. Eichorst SA, Kuske CR. Identification of cellulose-responsive bacterial and fungal communities in geographically and edaphically different soils by using stable isotope probing. Appl Environ Microbiol. 2012;78:2316-27.

80. Verastegui Y, Cheng J, Engel K, Kolczynski D, Mortimer S, Lavigne $\mathbf{J}$, et al. Multisubstrate isotope labeling and metagenomic analysis of active soil bacterial communities. mBio. 2014;5: e01157-14

81. Folman LB, Klein Gunnewiek PJA, Boddy L, de Boer W. Impact of white-rot fungi on numbers and community composition of bacteria colonizing beech wood from forest soil. FEMS Microbiol Ecol. 2008;63:181-91.

82. Valáková V, De Boer W, Klein Gunnewiek PJA, Pospíek M, Baldrian P. Phylogenetic composition and properties of bacteria coexisting with the fungus Hypholoma fasciculare in decaying wood. ISME J 2009;3:1218-21.

83. Smenderovac E. Microbial Community Structure and Function in Coarse Woody Debris and Boreal Forest Soil after Intensified Biomass Harvests. University of Toronto, PhD diss. 2014;140.

84. Henrici AT, Johnson DE. Studies of Freshwater Bacteria. J Bacteriol 1935;30:61-93.

85. Poindexter JS. The Caulobacters: ubiquitous unusual bacteria. Microbiol Rev. 1981;45:123-79. 
86. Nierman WC, Feldblyum TV, Laub MT, Paulsen IT, Nelson KE, Eisen J, et al. Complete genome sequence of Caulobacter crescentus. PNAS. 2001;98:4136-41.

87. Hottes AK, Meewan M, Yang D, Arana N, Romero P, McAdams $\mathrm{HH}$, et al. Transcriptional profiling of Caulobacter crescentus during growth on complex and minimal media. J Bacteriol 2004;186:1448-61.

88. Thanbichler M, Iniesta AA, Shapiro L. A comprehensive set of plasmids for vanillate - And xylose-inducible gene expression in Caulobacter crescentus. Nucleic Acids Res 2007;35.

89. Song Z, Vail A, Sadowsky MJ, Schilling JS. Influence of hyphal inoculum potential on the competitive success of fungi colonizing wood. Microb Ecol. 2015;69:758-67.

90. Presley GN, Payea MJ, Hurst LR, Egan AE, Martin BS, Periyannan GR. Extracellular gluco-oligosaccharide degradation by
Caulobacter crescentus. Microbiol (United Kingdom) 2014;160:635-45.

91. Wang X, Sharp CE, Jones GM, Grasby SE, Brady AL, Dunfield PF. Stable-isotope probing identifies uncultured Planctomycetes as primary degraders of a complex heteropolysaccharide in soil. Appl Environ Microbiol 2015;81: 4607-15.

92. Ausec L, van Elsas JD, Mandic-Mulec I. Two- and three-domain bacterial laccase-like genes are present in drained peat soils. Soil Biol Biochem 2011;43:975-83.

93. Colpa DI, Fraaije MW, Van Bloois E. DyP-type peroxidases: A promising and versatile class of enzymes. J Ind Microbiol Biotechnol 2014;41:1-7.

94. Singh R, Eltis LD. The multihued palette of dye-decolorizing peroxidases. Arch Biochem Biophys 2015;574:56-65. 